Twigger Holroyd, A., Cassidy, T., Evans, M. and Walker, S. (2017) 'Wrestling with Tradition: Revitalizing the Orkney Chair and Other Culturally Significant Crafts'. Design and Culture. Available at: http://dx.doi.org/10.1080/17547075.2017.1370310

\title{
Wrestling with Tradition: Revitalizing the Orkney Chair and Other Culturally Significant Crafts
}

This work was supported by the Arts \& Humanities Research Council under grant $\mathrm{AH} / \mathrm{K} 008021 / 1$.

Dr Amy Twigger Holroyd, Nottingham Trent University

Amy Twigger Holroyd is a designer, maker and researcher with expertise in the emerging field of fashion and sustainability. She is a Senior Lecturer in the School of Art \& Design at Nottingham Trent University.

amy-twigger.holroyd@ntu.ac.uk

Professor Tom Cassidy, University of Leeds

Tom Cassidy holds the Chair in Design at the University of Leeds. He is a Fellow of the Design Research Society and has extensive experience of teaching and research in textile technology and design.

T.Cassidy@,leeds.ac.uk

Professor Martyn Evans, Manchester Metropolitan University

Martyn Evans is Professor of Design and Head of Manchester School of Art Research

Centre at Manchester Metropolitan University. His research interests explore the strategic approaches designers use to consider the future.

Martyn.Evans@mmu.ac.uk

Professor Stuart Walker, Lancaster University

Stuart Walker is Professor of Design for Sustainability and Co-Director of the ImaginationLancaster research centre at Lancaster University. His research explores the theory and practice of design for sustainability.

s.walker@lancaster.ac.uk

\begin{abstract}
Across the world, "culturally significant" designs, products, and practices - such as traditional crafts - have been pushed to the margins by the forces of modernization and globalization. Appreciation of the positive attributes of these traditions drive widespread revitalization initiatives, often involving designers. Awareness of the cultural ramifications of design-led revitalization may deter enthusiasm for radical initiatives and instead promote preservation efforts. Yet a deconstruction of the popular understandings of tradition and origin indicates a need for change and cross-cultural contact. This article proposes that social value - central to a traditional craft's cultural significance - should be used to guide revitalization.
\end{abstract}

\section{Keywords}

tradition, craft, cultural significance, revitalization, Orkney chair 


\section{Introduction}

Across the world, "culturally significant" designs, products, and practices - such as traditional crafts - have been pushed to the margins by the forces of modernization and globalization. Yet countless efforts to revive and reinvent these aspects of material culture can be identified as communities recognize their importance in terms of identity, wellbeing, and environmental stewardship. Designers play a key role in revitalization initiatives, bringing new life to aspects of culture that are foundering in contemporary life. As such, designers play an influential role in shaping the interaction between tradition and innovation. They become entangled in complex cultural processes; every decision has potentially far-reaching implications in terms of significance and value.

In this article, we explore the cultural implications of design-led revitalization, with a particular focus on tradition and origin. Deconstructing the popular understandings of these concepts, we argue that change and cross-cultural contact are integral elements of tradition, rather than challenges to it. The straw-backed chairs associated with the Orkney Islands in Scotland provide a relevant case study. These chairs are a prime example of a traditional and locally rooted craft: they have been uniquely linked with Orkney for generations, valued by both the local community and a diaspora of those with links to the islands.

\section{Defining cultural significance}

First, we must explain what we mean by 'culturally significant designs, products, and practices'; this short phrase requires a surprising amount of unpacking. Putting the task of defining cultural significance to one side for a moment, we will start by identifying the type of products we are concerned with. These products have three key characteristics:

- Tangible (rather than intangible "products" such as dance and music) 
- Durable (rather than products that are completely consumed in one use such as food and drink)

- Portable (rather than permanent structures such as buildings)

We are, therefore, talking about physical artifacts such as furniture, jewellery, and tableware. It is important to stress that we are not concerned with singular artifacts - the specific items held in museum collections, for instance - but rather types of product, of which there will be countless individual examples. By "designs", we mean the surface patterns and three-dimensional forms associated with these products. By "practices", we mean the processes involved in their construction, use, and repair.

We are especially interested in designs, products, and practices that are significant to place-based cultures: local, regional, and national communities. But what does "significant" mean? The notion of cultural significance is widely discussed in relation to the conservation of heritage sites, and this work provides a useful starting point. De la Torre and Mason $(2002,3)$ suggest that "Cultural significance ... mean[s] the importance of a site as determined by the aggregate of values attributed to it." Borrowing this logic, we can say that a culturally significant design, product, or practice is one considered to be important due to the various values attributed to it. This leads to the next question: what do we mean by values? Mason $(2002,7)$ explains that in this context, values means "the qualities and characteristics seen in things, in particular the positive characteristics (actual and potential)". He argues that values are multiple and diverse: "In a given moment, a given heritage site, building, or object has a number of different values ascribed to it." (8) Furthermore, he continues, values are contingent on their cultural surroundings. "Values are produced out of the interaction of an artifact and its contexts; they don't emanate from the artifact itself." (8) 
Although values cannot be objectively measured, they can be productively explored and assessed. Various typologies of values have been developed in terms of heritage sites. As Mason $(2002,10)$ explains, while different typologies reflect differences in epistemology and the priorities of their creators, there are many commonalities: "In most instances, they describe the same pie, but slice it in subtly different ways." The Australian National Committee of the International Council on Monuments and Sites (Australia ICOMOS 2013), for example, organizes values into five categories: aesthetic, historic, scientific, social, and spiritual. The categorization used by English Heritage (2008) comprises aesthetic, historical, evidential, and communal value. Mason emphasizes that one typology will not speak equally well to all cultural milieus, and encourages the development of new typologies, where required. Thus, we have adapted the typologies identified above for our domain of designs, products, and practices. The resulting categorization comprises social, historical, and aesthetic values, as briefly described below:

- Social value refers to the associations that a design, product, or practice has for a particular cultural group and the social, cultural, or spiritual meanings that it holds for them. Social value may reflect a sense of identity, distinctiveness, and social interaction.

- Historical value derives from the ways in which aspects of life from the past can be connected to the present through designs, products, and practices. It may be based on the length of time a tradition has developed, its association with specific people or events, or its rarity and/or uniqueness. 
- Aesthetic value refers to the visual, sensory, and perceptual experience of a design, product, or practice. It includes artefacts and patterns with uncommonly attractive or distinctive qualities which evoke strong feelings or special meanings.

To be deemed culturally significant, a design, product, or practice would need to have a strong sense of value across these three categories. Because we are primarily interested in significance felt within a community, we place the greatest emphasis on social value; historical and aesthetic value should be seen - for our purposes - as supporting elements. By using this typology, our understanding of cultural significance is guided by the values felt by the communities in question and thus can be adapted to diverse contexts. Despite this flexibility, it is important to note that traditional crafts typically meet these criteria. Craft designs, artifacts, and practices often carry great meaning for the communities within which they are embedded. Crafts are frequently noted for their distinctive aesthetic qualities, while longstanding traditions offer clear links with aspects of life from the past. Thus, as an important grouping within the wider sphere of culturally significant designs, products, and practices, traditional crafts will be used as a focus throughout the following discussion.

The Orkney chair (Figure 1) is a distinctive vernacular item of furniture, with a straw back and wooden seat. The straw back may be curved or follow straighter lines; some incorporate a hood to offer protection against draughts or noise (Carruthers 2009). Drawers are often incorporated under the seat, and are thought to have been used in the past to store reading material, tobacco, and alcohol (Cotton 2008). The distinctive design of the chair derives from materials available on the remote Orkney Islands, as Cotton describes: 
On the largely treeless Northern Isles, where wood was harvested as "found" timber, often on the foreshore, or purchased as an expensive import, straw became an important and effective alternative material from which to make many items for which sawn wood or wicker might otherwise have been used. The straw of the indigenous black oats was used, and the locally grown bent or marram grass was twisted to form a strong cord. (Cotton 2008, 250)

Carruthers (2009) explains that in the nineteenth century, crofters and fishermen would have made chairs for their own use from these materials. Orkney chairs are still made on the islands today, with a few professional makers selling their work to locals, tourists, and via the internet. Amateurs also make their own chairs, as in the example shown in Figure 2. The chair is traditional, with a documented history of craft making that can be traced back at least 200 years. It has a clear link with place: its distinctive form is derived from the materials that are naturally available on the islands. Carruthers $(2009,42)$ argues that the chair is important to the local community, explaining that "for Orcadians at home and abroad it has become over the past century an important reminder of a resilient local culture."

\section{Revitalization}

The cultural trajectory of the Orkney chair, as with so many other traditional and local craft products across the world, has been shaped by the fundamental changes associated with modernization, industrialization, and globalization. While these social, political, and economic transformations take different forms in different contexts, common challenges can be identified. For example, craft products struggle to compete against mass-produced alternatives in the marketplace, while craft makers are attracted by the benefits of alternative employment. The sense of progress associated with modernization makes traditional artifacts and practices seem old-fashioned and unappealing; moreover, changes in lifestyle render them obsolete. 
Despite the many challenges, there is evidence that the processes of modernization and globalization are stimulating desire for traditional crafts: "For a period, many believed that industrialization would kill craft. Similarly, globalization would kill local cultural expressions ... However, this prognosis of extinction was not confirmed. There are many clues to the contrary; that the place of craft in our modern society is expanding." (Borges 2011, 203) What are these clues? We might highlight the fact that artisan crafts offer the authenticity felt to be lacking in mass-produced goods, and in postmodern culture more broadly (Boyle 2004). They contribute to local distinctiveness - the unique particularities of specific places - and thus appeal to those who are frustrated by the sense that "everywhere is becoming the same as everywhere else" (Kingsnorth 2008, 7). Meanwhile, longstanding traditions provide a welcome sense of stability in a culture of constant change. As West $(2012,13)$ argues, "tradition ... can be of great use in a liquid modern world, a questioning, solidifying force, and a reminder that society cannot spend its entire time in the fast lane." Amidst all this is a growing interest in hands-on making and amateur creativity (Gauntlett 2011). These multiple factors drive efforts to revitalize craft traditions, including - as we will explain - the Orkney chair.

The term "revitalization" is used here to describe any initiative that aims to bring new life to a culturally significant design, product, or practice. The central activity of the research underpinning this article was the development of a taxonomy of revitalization strategies, built by analyzing over 400 examples of revitalization and considering the relationship of these initiatives to the traditions upon which they build. Over 40 distinct strategies were identified, organized into eight clusters that range in scale from the specification of a single product to high-level infrastructure initiatives. The clusters include strategies that address the redesign of products and the reinterpretation of patterns and forms; emphasize connections with place; explore aspects of production, skills 
transfer, and promotion; and pursue more holistic approaches to support effective organization, research, and education. An intentionally broad view of revitalization was adopted, accommodating both market-led and amateur initiatives and encompassing strategies that translate a culturally significant design to an entirely new context alongside those that invigorate a craft in its traditional guise. By allowing for radical reinventions, this definition of revitalization is rather different from the conservation approach applied to heritage sites. As explained in the Australia ICOMOS Burra Charter for culturally significant sites, conservation "requires a cautious approach of changing as much as necessary but as little as possible" (Australia ICOMOS 2013, 3).

The case study of the Orkney chair provides a clear example of revitalization. The Brodgar Chair (Figure 3) is "a contemporary Orkney chair combining an oaken Windsor chair vernacular with the traditional Orkney chair straw back" (The New Craftsmen 2017a). The design was created in 2012 as a collaboration between traditional Orkney chair maker Kevin Gauld and furniture designer-maker Gareth Neal. Gauld is a highly skilled maker, having started his career with an apprenticeship at the age of 16. Neal's acclaimed designs have been sold and exhibited internationally; he is known for combining traditional craftsmanship with digital tools. The collaboration was organized by The New Craftsmen, a gallery in London's upmarket Mayfair district. The gallery promotes "contemporary objects rooted in craftsmanship" sourced from around the British Isles, aiming "to forge collaborations with designers and makers to give a contemporary take on specific skills and materials" (The New Craftsmen 2017b). As such the gallery fits into a small but growing movement that seeks to support the sustainment of heritage crafts in Britain. In this example, two key revitalization strategies can be identified: developing a fresh aesthetic through the "mash-up" of two traditional forms, and promoting the product to new markets through a sophisticated selling platform. 


\section{The designer's role}

As demonstrated in the case of the Brodgar Chair, designers are often involved in the revitalization of traditional crafts, applying their skills across a diverse range of strategies. Design-led interventions have a long history; across the world, crafts have been commercialized and refined as a means of economic and social development for over 150 years (Salmond 1996; Friel and Santagata 2008). The designer is frequently seen as a "bridge" between maker and market, bringing valuable knowledge of consumer demands and contemporary tastes (Craft Revival Trust 2005). For those who are anxious about a traditional craft dying out, design can appear to be a savior: a magical elixir of cultural capital and creative innovation that will guarantee survival. Yet designers must make critical judgements as they shape their creative strategies, negotiating the tension between contemporary tastes and the preservation of an authentic traditional culture. If they push for too much change, or work without the approval of the artisans, they risk disrupting the society within which the crafts are embedded (Craft Revival Trust 2005). Thus, the success of a revitalization initiative is far from guaranteed; in fact, criteria for success are likely to vary widely between stakeholders.

In her writing about revitalization projects in Brazil, Borges (2011) highlights a range of problems that arise in encounters between designers and artisans. She raises the issue of designers being "parachuted in" for short-term projects, when long-term commitment is required to develop a true understanding of the craft and cultural context. In this situation, there is a tendency to employ pre-existing design ideas, and to work on the basis of crude preconceptions. While the results of a short-term design intervention may be aesthetically engaging, they are unlikely to provide any lasting benefit to the craft or the artisan community. Borges also describes an imbalance of power at the heart of 
many projects, with professional designers from urban backgrounds feeling - consciously or subconsciously - superior to rural craftspeople, who may lack formal education. Murray $(2015,226)$ agrees that such relationships "subscribe to a hierarchy that places emphasis on the creative agency of the designer." These issues are not unavoidable; Borges identifies initiatives in which designers and makers collaborate together on equal terms and produce lasting positive results. She argues that when working with artisans, designers should act as facilitator rather than author, empowering the makers to develop their own creativity. Murray $(2015,229)$ describes "an ethical ideal of mutual respect, in which both partners are positioned as active agents with their own interests." Yet it is difficult to ignore the argument that well-intentioned Western designers working with craftspeople in the global South might inadvertently collude in promulgating an idea of such cultures as dependent (Ladd 2012). As Nussbaum (2010) asks: "is humanitarian design the new imperialism?"

While the issues highlighted by Borges and others relate primarily to projects in less economically developed countries, the principles hold true for post-industrial contexts: in many cases, designers plunge into revitalization projects with little awareness of the political, social, and moral dimensions of their actions. Even if designers are not working directly with craft makers - if, for example, they are interpreting traditional patterns using a new technology - problems can arise. For example, the use of indigenous cultural heritage in commercial design contexts prompts concerns about the issue of cultural appropriation (Shand 2002). Should designers gain an understanding of the cultural minefield that surrounds the seemingly clear-cut challenge of revitalization, they may become reluctant to intervene. Given the many potential pitfalls awaiting any proposed solution, it could seem better to leave a tradition to adapt "organically", without any input from outsiders. Alternatively, they may decide to reject radical intervention 
ideas, opting instead for a conservative approach out of respect to the cultural significance of a tradition. From this perspective, we might question the success of the Brodgar Chair initiative, which eliminates a number of the recognized characteristics of the Orkney chair. It could be argued that this well-meaning attempt at revitalization is actually an affront to a longstanding and unique tradition and that this intervention, orchestrated by a London gallery, lessens the distinctiveness and authenticity of a locally rooted artifact. Yet a hands-off attitude carries its own, perhaps less apparent, dangers. To understand these dangers, we must interrogate the notions of tradition and origin that so often sit at the heart of cultural significance.

\section{Tradition}

The sociologist Edward Shils has explored the meaning of tradition as a common phenomenon in human culture. In its simplest sense, he argues, tradition is "anything which is transmitted or handed down from the past to the present" (Shils 1981, 12). Shils explains that these things that are handed down - which he describes as "patterns" - could include objects, beliefs, and practices. The popular understanding of tradition assumes that such patterns will remain static over time; innovation is frequently seen as a challenge to authenticity. Shils' work challenges this notion. He explains that traditions evolve in the process of transmission; indeed, it is this ability to adapt that allows traditions to remain relevant in the long term. Therefore, detailed accounts of specific craft traditions - such as Bunn's (2011) work on felt-making in Kyrgyzstan and the research by Stankard (2010) into Malaysian hand-woven textiles - describe cultures of creativity and innovation. According to basket-maker Joe Hogan, who has studied the diversity of vernacular baskets in Ireland, "from the outside, traditional work can look very static, but the closer you get, the more you realise that it's experimental" (quoted by Lloyd-Jones 2014, 35). This sense 
of creativity can be readily observed in the case of the Orkney chair. Although only a small number of examples can be found in museum collections, they reveal a significant degree of variation. As already described, the chairs may have curved or straight straw backs, and be constructed with or without the protective hood and under-seat drawer. Chairs vary further in terms of size, proportion, and construction; some examples have straw panels under the arms, and some are upholstered with fabric over the straw (Cotton 2008).

Traditions are generally thought to be authentic and longstanding. If we learn a "traditional" dance, eat "traditional" food, or wear "traditional" clothes, we tend to feel that we are connecting with an unbroken chain of shared activity, stretching far into the past. Yet in many cases, this is a fundamental misconception. Hobsbawm (1983) describes "invented traditions": consciously constructed practices that claim significant and artificial links with history. For example, although the association of tartan with particular Scottish clans is popularly assumed to date back to medieval times, this tradition only came about as part of a pageant devised by Sir Walter Scott in 1822 (Trevor-Roper 1983). Despite this invented history, the sense of identity and belonging associated with particular tartan designs carries a high level of social value. As Faiers $(2008,279)$ argues, the myths surrounding invented traditions such as tartan quickly become "embedded in popular consciousness" and thus develop cultural significance.

Even if not artificially invented, many traditions have been subject to previous rounds of strategic design intervention. The "traditional" Orkney chair, as recognized today, was significantly shaped by a revitalization initiative in the late nineteenth century. David Munro Kirkness, a joiner based in the town of Kirkwall in Orkney, commercialized the chair, refining and standardizing the vernacular form into four designs. His work was exhibited at the Scottish International Exhibition in 1890 and subsequently found an 
international market (Carruthers 2009). The chairs quickly became fashionable, supported by the ethos of the Arts \& Crafts movement: "by 1909, retailers such as Liberty of London were ordering over 40 chairs a month" (Victoria and Albert Museum 2016). Thousands of chairs were sold to customers in mainland Great Britain, Australia, Canada, India, South Africa, and South America, as well as in Orkney itself. Kirkness' design has proved to be enduring; Orkney chairs made today - including the one shown in Figure 1 - are typically based on the refined version that he developed over a century ago (Carruthers 2009). Given the significance of the Orkney chair to Orcadians today, we must conclude that instrumental - and market-driven - revitalization initiatives are no barrier to cultural meaning and social value.

Overall, there is a strong argument that changes in terms of design and use, including somewhat radical revitalizations such as the Brodgar Chair, should be seen as part and parcel of an evolving tradition, rather than unwelcome encroachments on a pure and authentic pattern. Others working in the field of design and revitalization have noted the importance of change. Adhi Nugraha, a designer who has been involved in the revitalization of a range of traditional Indonesian crafts, argues that "to preserve tradition means to continuously develop it" (Nugraha 2010, 34). Indeed, as anthropologist Antonio Arantes points out, "practice as social action cannot be preserved. It has to change in order to stay the same" (quoted by Borges 2011, 139). It is important to note that the degree to which this perspective is embraced can vary according to the context. Baker (1997) highlights a hidden double standard that can be identified in discussions about craft traditions. Innovation in Western craft contexts is often considered to signal a sophisticated navigation of what has been described as "the interface between tradition and modernity" (Craft Revival Trust 2005, 4). Yet there is an unspoken assumption that non-Western communities should not "betray tradition" by adapting their local crafts to 
changing times. This assumption overlaps with the modern temptation to romanticize craft, especially in contexts considered to be exotic.

\section{Origin}

The notion of origin is another crucial concept in terms of cultural significance.

Traditional designs, products, and practices are often considered to have "roots": links to specific locations where they originated and developed. Indeed, places are frequently included in the names we use for culturally significant items: consider, to select three British examples, Welsh lovespoons, Worcester porcelain and, of course, the Orkney chair. Many feel that the distinctive links that connect artifacts with specific locations should be protected against the placelessness of globalization. Various schemes have been developed to support this protection, from the worldwide geographical indication system to localized schemes such as the Sámi official label of authenticity (Cocq 2014). These initiatives help artisan communities whose livelihoods are threatened by mass-produced copies of local crafts, imported from distant countries with lower labor costs. Yet the "tidying up" of connections between traditional crafts and particular places belies the fact that the notion of origin can be as deceptive as that of tradition.

Many designs, products, and practices that we consider to be representative of a specific place have been consciously constructed as such, whether through organized initiatives or strategic marketing campaigns. This is especially noticeable in the case of dress. Roces and Edwards $(2007,5)$ describe a range of cases in which traditional clothing has been actively manipulated by political regimes, arguing that "the invention of national dress has been an important aspect of nation-building in Asia and the Americas". Constructed links between product and place can also occur on a more local level. The One Village, One Product strategy was introduced in Japan in the 1970s to revitalize rural 
economies and required localities to each specialize in one unique product. The strategy has since been introduced in other Asian, African, and Latin American countries. For example, the Bang Chao Cha sub-district in Thailand specializes in high quality crafted bamboo items as part of the country's One Tambon, One Product initiative (Chotiratanapinun 2011). Something similar can be observed in our case study of the Orkney chair; it was only when Kirkness' nineteenth century chairs were actively promoted in mainland Britain and overseas that they became icons of Orkney life (Cotton 2008). The chairs "fitted into a romantic view of Scottishness at the turn of the century, and the idea that a well-crafted object could embody local or national identity" (Victoria and Albert Museum 2016).

The notion of a pure and uncontaminated link with place is further challenged by close examination of the history of "local" designs, products, and practices. Historical investigations reveal instances of intracultural diffusion - whether through colonization, migration, or trade - through which patterns and processes have moved around the world (Hann 2013). Consider, for example, the Paisley pattern (Figure 4). Most frequently used in printed textiles today, the distinctive pattern gained its name because of its use by weavers in the town of Paisley in the nineteenth century. However, the pattern did not originate in Scotland; in fact, the distinctive designs used by the Paisley weavers - along with weavers in Norwich, Edinburgh, and Paris - were copied from shawls imported from Kashmir. Tracing the story further, evidence suggests that the pattern originated in ancient Babylon (Reilly 1987). Thus, the "origins" of a cultural form are often much less straightforward than they may first appear. It is useful to apply the thinking of the cultural theorist Stuart Hall, who suggested that "instead of asking what are people's roots, we ought to think about what are their routes, the different points by which they have come to be" (Hall 1999). 
What are the origins of the straw-backed Orkney chair? A local historian in the early 1890s claimed that the wood and straw chair was invented by a local man in the first half of the eighteenth century, and this narrative has been repeated in many subsequent accounts (Carruthers 2009). Yet there is a lack of evidence to support this claim; the earliest surviving Orkney chairs date from only the nineteenth century. In fact, Carruthers suggests that the practice of constructing chairs from straw may have been introduced from England, where the practice dates back to the seventeenth century. Cotton (2008) explains that similar chairs were made in Denmark, indicating another potential source of cross-cultural influence. An alternative theory, proposed in a report of 1914, is that the straw-backed chair was directly influenced by the straw-plaiting industry that was introduced to Orkney by a London-based company in 1804 (Carruthers 2009, 29). Whatever the truth, the point is that external origins do not diminish the social, historical, and aesthetic values associated with the chair today.

\section{An alternative approach}

How might this knowledge about tradition and origin affect designers' feelings about revitalization? This discussion has indicated that a lack of intervention is potentially more harmful than radical change. In fact, caution creates a misleading sense of stability. Traditions that are not supported to evolve will die out, their cultural significance vanishing into the ether. As Shils $(1981,14)$ points out, "traditions are not independently self-reproductive or self-elaborating"; they are enacted and passed on by individuals and communities only if they are considered to be relevant, interesting, and useful.

Preservation is no panacea; if we fall into the trap of forcing culturally significant products and practices to become static, they will effectively become invented traditions, existing only to offer a hollow sense of history. 
An alternative approach is required for the designer who sees the importance of revitalization yet wishes to avoid the cultural pitfalls associated with this activity. We propose that value - and particularly social value, the key component of cultural significance - should be used as a guide. From this perspective, revitalization initiatives should aim to bring new life to a culturally significant design, product, or practice, while retaining (or even enhancing) the values associated with it. That is, the intervention must maintain or develop the associations that a design, product, or practice has for a particular cultural group and the social, cultural, or spiritual meanings that it holds for them. By placing an emphasis on associations and meanings rather than specifics of form or process, this approach to revitalization is dynamic and flexible. It allows for both radical reinterpretations and much more conservative approaches - provided the strategy selected supports the tradition to continue in a way that carries meaning for the community with which it is connected.

In practical terms, the facilitators of a revitalization initiative would need to assess the social, historical, and aesthetic values attributed to a traditional craft. They would need to consider the condition of the tradition: thriving, surviving, in decline, or on the edge of extinction? An appraisal of the context would also be required in order to identify key threats and opportunities shaping the options for the tradition's future. Armed with this information, a range of potential strategies could be developed; these options could then be assessed in terms of values, with a particular emphasis on social value. An assessment of the Brodgar Chair initiative might conclude that the meanings associated with the traditional Orkney chair - local resourcefulness, for example - were strengthened as the narrative surrounding the new interpretation highlighted this aspect of the tradition's development. Furthermore, it could be argued that this new interpretation stimulated interest in the tradition more widely; the new design did not replace the existing form, but 
rather contributed another aesthetic option, broadening the product's appeal. Of course, a revitalization may have mixed effects in terms of values: strengthening meanings and associations in some ways (or for some people), yet diminishing them in others. There may be clashes between social, historical, and aesthetic values, requiring careful trade-offs and culturally sensitive decisions. More fundamentally, there would be great difficulties in making these assessments for proposed options, given that it is difficult to predict how new ideas will take root in culture. Still, an emphasis on values - and social values in particular - provides a valuable thread to guide designers and others engaged in revitalization.

\section{Conclusion}

This article has examined the revitalization of culturally significant products - tangible, durable, and portable artifacts that are connected to local, regional, or national cultures and the designs and practices associated with them. By adapting work from the field of built heritage, we propose that to be deemed culturally significant, a design, product, or practice must carry social, historical, and aesthetic values. We place a particular emphasis on social value, which refers to the social, cultural, or spiritual meanings that a design, product, or practice holds for a particular cultural group. Traditional crafts typically meet these criteria in that they contribute to a sense of identity, are locally distinctive, and tend to support social interaction between makers and users.

Culturally significant designs, products, and practices across the world face common challenges associated with modernization, industrialization, and globalization. Yet modernizing forces can also stimulate our desire for tradition and local distinctiveness. Longstanding traditions give us a sense of stability in a culture of constant change, while artisan crafts offer the authenticity felt to be lacking in mass-produced 
goods. This desire drives revitalization initiatives: efforts that aim to bring new life to a culturally significant form. Initiatives vary in terms of approach, from conservative interventions that seek to maintain as much of a tradition as possible to much more radical reinterpretations. The Orkney chair has provided a case study to consider various dimensions of revitalization, tradition, and origin. Although this craft artifact is considered to be authentically rooted in the Orkney Islands, its history reveals external influences and instances of strategic market-led revitalization.

Designers occupy a highly influential role in revitalization initiatives, contributing to the evolution of cultural forms that provide a sense of belonging and distinctiveness. Yet awareness of the complex cultural ramifications of such activities could make designers reluctant to engage, choosing instead to allow traditions to survive on their own terms. We argue that a second level of awareness is needed: awareness that evolution and change are integral elements of tradition, and that simplistic narratives connecting products and places gloss over complex histories of cross-cultural influence. Failure to intervene in a declining tradition could have a more detrimental effect than a controversially bold design initiative. Armed with this understanding, designers should be in a better place to innovate and explore the future potential of rich traditions, undaunted by claims of authenticity and rootedness.

We propose that the values that comprise cultural significance - especially social value - should be used to guide revitalization. Initiatives should aim to bring new life to a culturally significant design, product, or practice, while retaining (or even enhancing) the values associated with it. This approach requires designers to critically assess the cultural significance of a tradition and of their proposed solutions - challenges which potentially reshape the role of the designer. Processes for assessment and an understanding of the skills required can be adapted from the sphere of built heritage, where discussions of 
cultural significance are much advanced. Yet careful consideration will need to be given

to the ways in which these established approaches are translated to the diverse,

contradictory, and ever-shifting world of material culture.

\section{References}

Australia ICOMOS. 2013. The Burra Charter: The Australia ICOMOS Charter for Places of Cultural Significance. Burwood.

Baker, Patricia L. 1997. "20th Century Myth-making: Persian Tribal Rugs.” In Obscure Objects of Desire: Reviewing the Crafts in the Twentieth Century, edited by Tanya Harrod, 126-35. London: Crafts Council.

Borges, Adélia. 2011. Design + Craft: the Brazilian Path. São Paulo: Editora Terceiro Nome.

Boyle, David. 2004. Authenticity: Brands, Fakes, Spin and the Lust for Real Life. London: Harper Perennial.

Bunn, Stephanie. 2011. "Felt as a Change-Maker in Contemporary Kyrgyzstan." Making Futures 2. http://mfarchive.plymouthart.ac.uk/journalvol2/pdf/Bunn_Stephanie.pdf

Carruthers, Annette. 2009. "The Social Rise of the Orkney Chair." Journal of Design History 22 (1): 27-45. doi:10.1093/jdh/epn040.

Chotiratanapinun, Treechada. 2011. "Bamboo for Life: An Exploration of Bamboo Craft Practices in Thailand." Making Futures 2.

http://mfarchive.plymouthart.ac.uk/journalvol2/pdf/Chotiratanapinun_Treechada.pdf

Cocq, Coppélie. 2014. "Traditionalisation for Revitalisation: Tradition as a Concept and Practice in Contemporary Sámi Contexts." Folklore 57: 79-100. doi:10.7592/FEJF2014.57.cocq.

Cotton, Bernard D. 2008. Scottish Vernacular Furniture. London: Thames \& Hudson.

Craft Revival Trust. 2005. Designer Meet Artisans: A Practical Guide. New Delhi: Craft Revival Trust.

de la Torre, Marta, and Mason, Randall. 2002. "Introduction." In Assessing the Values of Cultural Heritage, edited by Marta de la Torre, 3-4. Los Angeles, CA: The Getty Conservation Institute.

English Heritage. 2008. Conservation Principles: Policies and Guidance for the Sustainable Management of the Historic Environment. London.

Faiers, Jonathan. 2008. Tartan. Oxford: Berg.

Friel, Martha and Walter Santagata. 2008. "Making Material Cultural Heritage Work: From Traditional Handicrafts to Soft Industrial Design." In The Cultural Economy, edited by Helmut Anheier and Yudhishthir Raj Isar, 274-83. London: SAGE.

Gauntlett, David. 2011. Making is Connecting. Cambridge: Polity.

Hall, Stuart. 1999. “A Conversation with Stuart Hall." The Journal of the International Institute 7 (1). http://hdl.handle.net/2027/spo.4750978.0007.107.

Hann, Michael. 2013. Symbol, Pattern \& Symmetry: The Cultural Significance of Structure. London: Bloomsbury Academic. 
Hobsbawm, Eric. 1983. "Introduction: Inventing Traditions." In The Invention of Tradition, edited by Eric Hobsbawm and Terence Ranger, 1-14. Cambridge: Cambridge University Press.

Kingsnorth, Paul. 2008. Real England: The Battle Against the Bland. London: Portobello Books.

Ladd, Katherine. 2012. "A Handmade Future: the Impact of Design on the Production and Consumption of Contemporary West African Craft as a Tool for Sustainable Development." Ph.D diss.. University of Brighton.

Lloyd-Jones, Teleri. 2014. "Joe Hogan: a Way With Willow." Crafts (248): 30-5.

Mason, Randall. 2002. "Assessing Values in Conservation Planning”. In Assessing the Values of Cultural Heritage, edited by Marta de la Torre, 5-30. Los Angeles, CA: The Getty Conservation Institute.

Murray, Kevin. 2015. "Social Sutra: A Platform for Ethical Textiles in Partnerships between Australia and India." In Cultural Threads: Transnational Textiles Today, edited by Jessica Hemmings, 224-49. London: Bloomsbury Academic.

Nugraha, Adhi. 2010. "Transforming tradition for sustainability through 'TCUSM' tool." Synnyt/Origins (3): 20-36.

Nussbaum, Bruce. 2010. “Is Humanitarian Design the New Imperialism?” Fast Company, July 6. http://www.fastcodesign.com/1661859/is-humanitarian-design-the-newimperialism

Reilly, Valerie. 1987. The Paisley Pattern. Glasgow: Richard Drew.

Roces, Mina, and Louise Edwards, eds. 2007. The Politics of Dress in Asia and the Americas. Eastbourne: Sussex Academic Press.

Salmond, Wendy R. 1996. Arts and Crafts in Late Imperial Russia: Reviving the Kustar Art Industries, 1870-1917. Cambridge: Cambridge University Press.

Shand, Peter. 2002. "Scenes from the Colonial Catwalk: Cultural Appropriation, Intellectual Property Rights, and Fashion." Cultural Analysis 3: 47-88.

Shils, Edward. 1981. Tradition. London: Faber.

Stankard, Suzanne. 2010. "Textile Praxis: The Case for Malaysian Hand-Woven Songket." PhD diss., Royal College of Art.

Taylor, Lou. 1997. "State Involvement With Peasant Crafts in East/Central Europe 194797: the Cases of Poland and Romania." In Obscure Objects of Desire: Reviewing the Crafts in the Twentieth Century, edited by Tanya Harrod, 53-65. London: Crafts Council.

The New Craftsmen. 2017a. "Brodgar Chair." The New Craftsmen. Accessed February 15 2017. https://www.thenewcraftsmen.com/product/brodgar-chair/

The New Craftsmen. 2017b. "Craftsmanship from the British Isles." The New Craftsmen. Accessed February 15 2017. https://www.thenewcraftsmen.com/about/

Trevor-Roper, Hugh. 1983. "The Invention of Tradition: the Highland Tradition of Scotland." In The Invention of Tradition, edited by Eric Hobsbawm and Terence Ranger, 15-42. Cambridge: Cambridge University Press.

Victoria and Albert Museum. 2016. "David Kirkness." Victoria and Albert Museum. http://www.vam.ac.uk/content/articles/d/david-kirkness/

West, Gary. 2012. Voicing Scotland: Folk, Culture, Nation. Glasgow: Luath Press. 


\section{Figure captions}

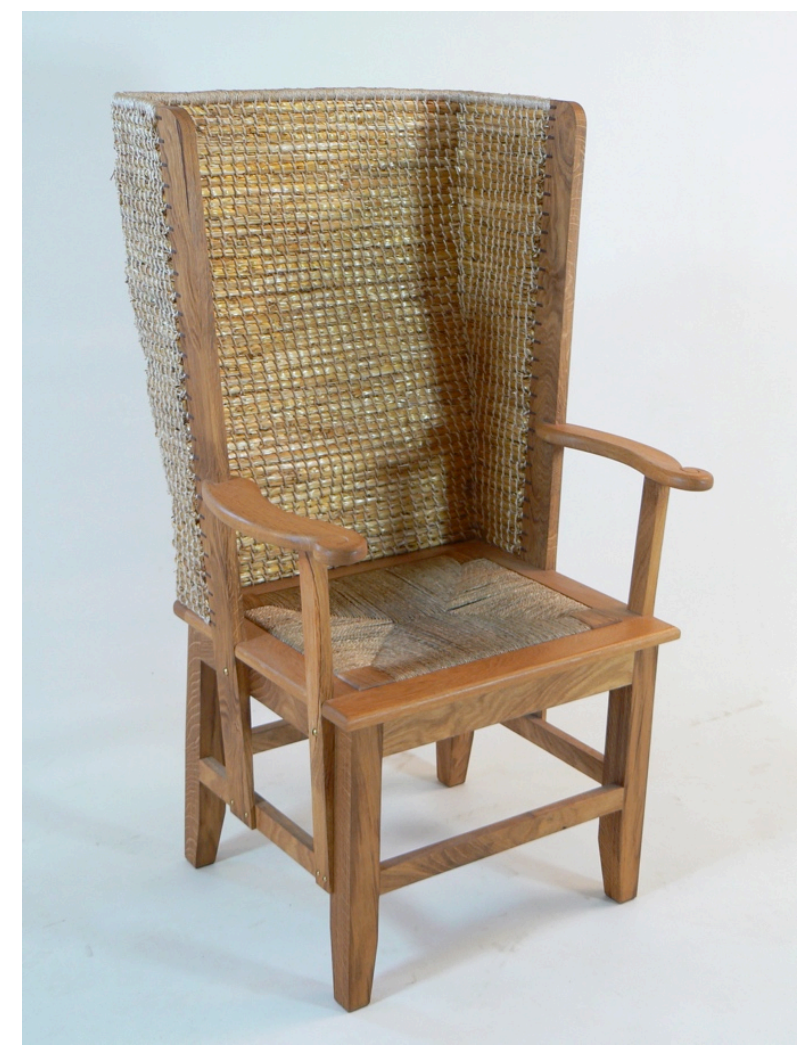

Figure 1: Gents' Orkney Chair in Scottish Oak by Kevin Gauld, The Orkney Furniture Maker. Courtesy of Kevin Gauld.

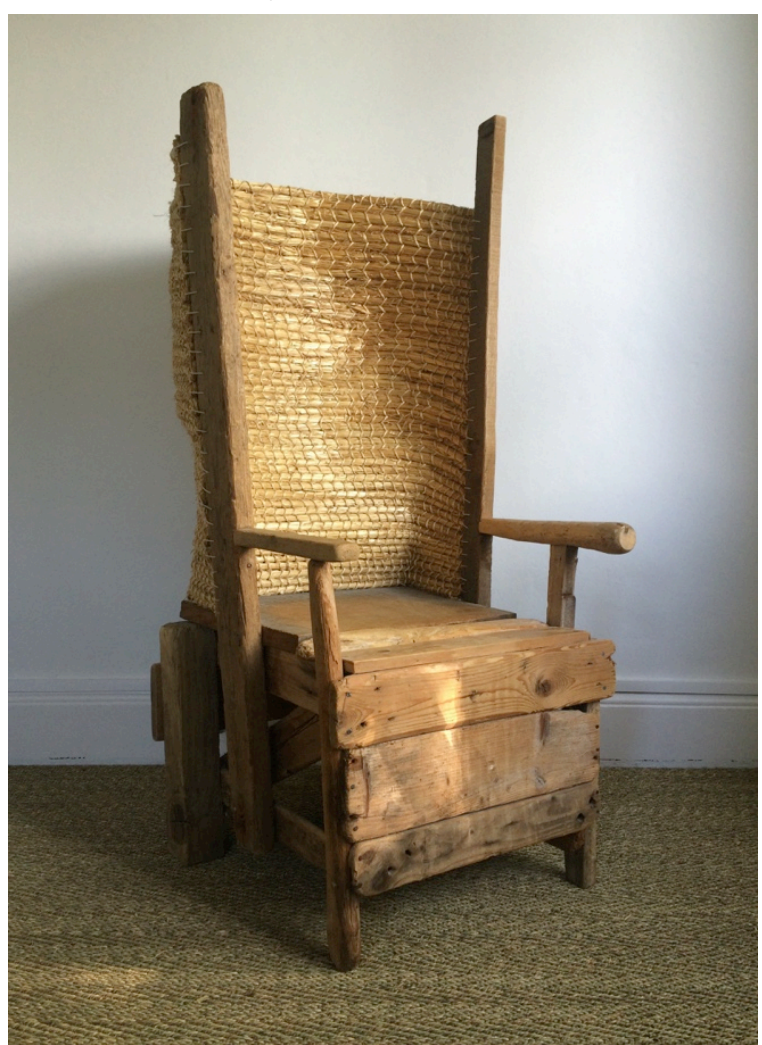

Figure 2: Orkney chair, made in 2004 by Juliet Arnott. Photograph: Katy Frances Shields. 


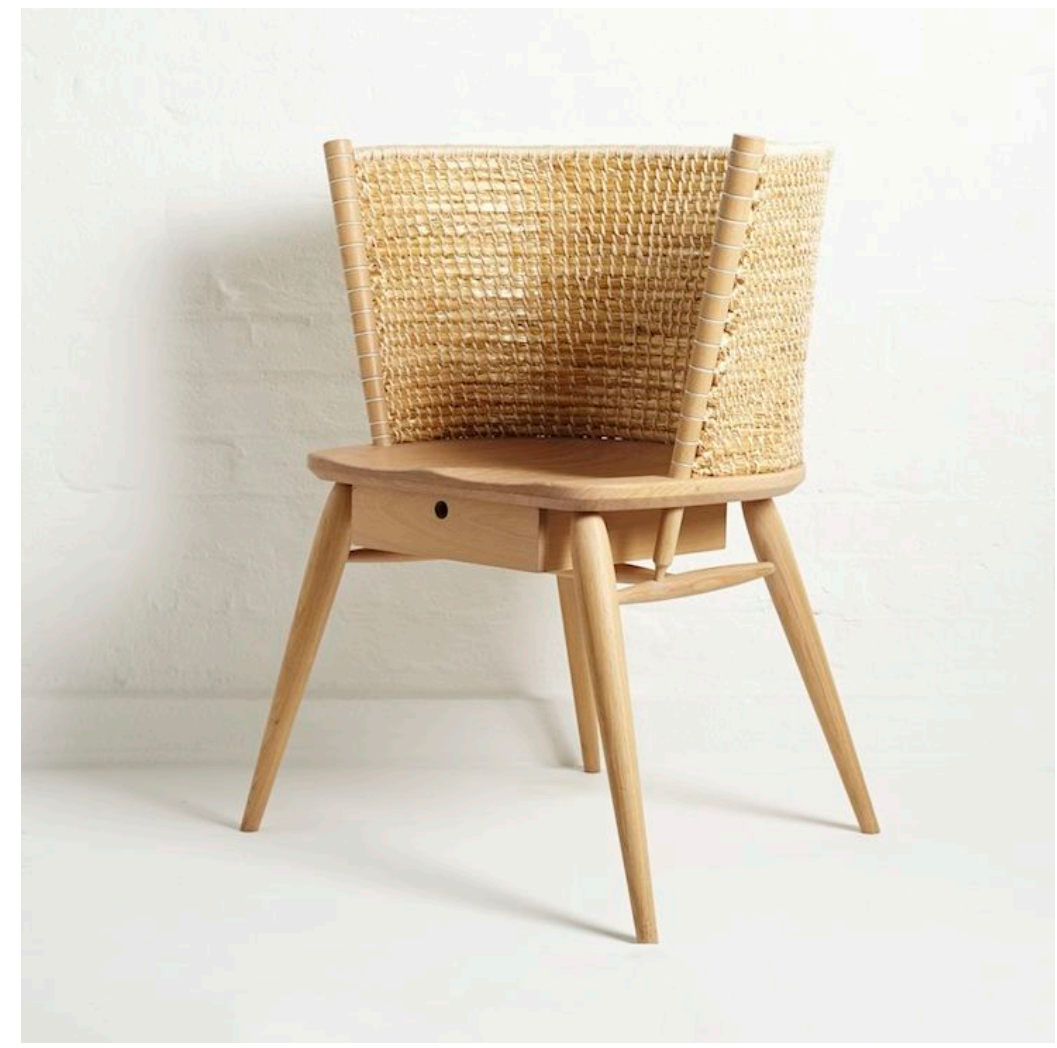

Figure 3: Brodgar Chair by Gareth Neal and Kevin Gauld. Courtesy of The New Craftsmen.

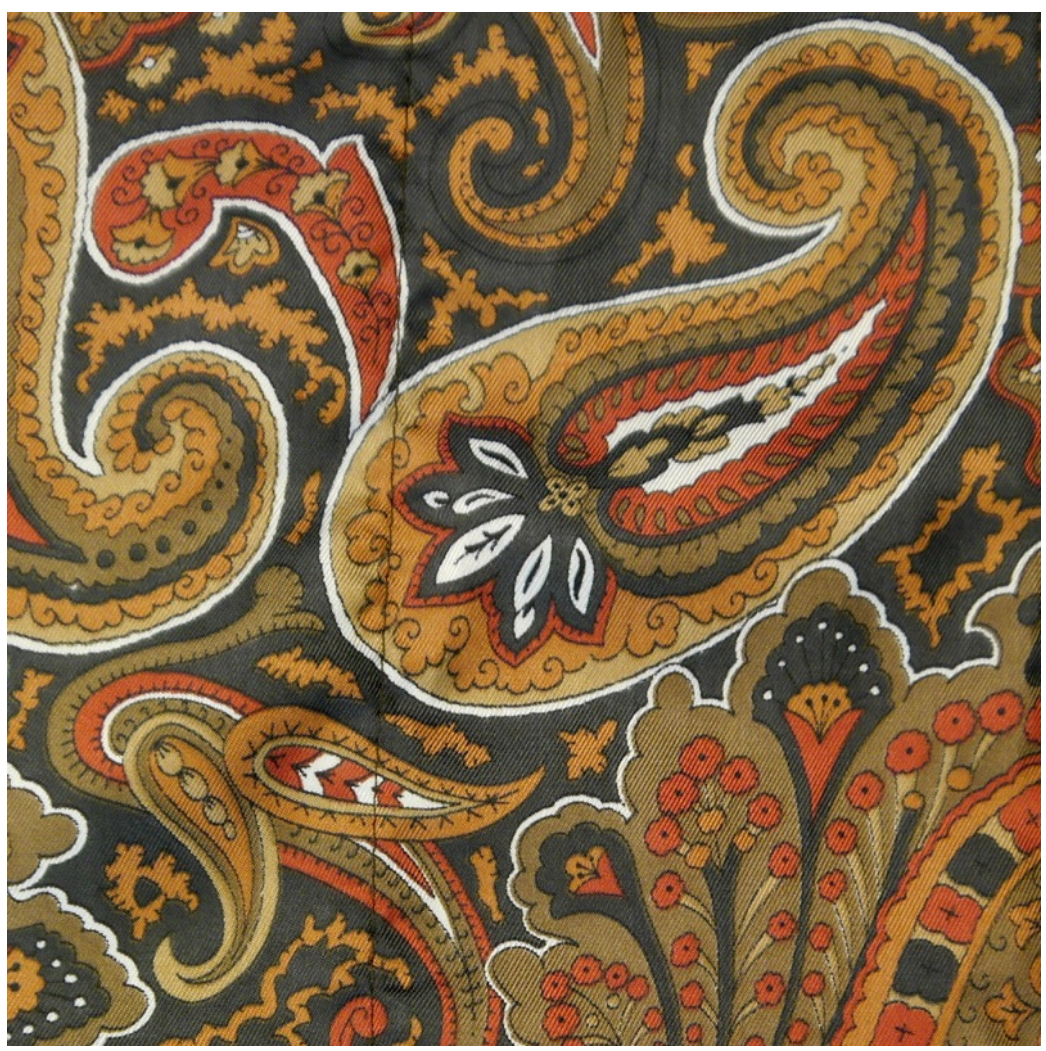

Figure 4: Paisley pattern, detail of men's dressing gown, 1974. Courtesy of The M\&S Company Archive. 